\title{
Improvement of the low knowledge, attitude and practice of hepatitis $B$ virus infection among Saudi national guard personnel after educational intervention
}

\author{
Majid S Al-Thaqafy ${ }^{1}$, Hanan H Balkhy², Ziad Memish³, Yahya M Makhdom, Adel Ibrahim, \\ Abdulfattah Al-Amri ${ }^{6}$ and Abdulhakeem Al-Thaqafi ${ }^{{ }^{*}}$
}

\begin{abstract}
Background: Although the risk of hepatitis B virus (HBV) was reported to be higher in military personnel than the general population in Saudi Arabia (SA), there is lack of studies assessing HBV awareness among them. The objective was to evaluate the knowledge, attitude and practice (KAP) of HBV infection among military personnel.

Methods: An intervention design with pre- and post-education KAP questionnaire was completed among National Guard soldiers working in Jeddah during January 2009. Educational intervention was provided through educational leaflets, group and individual discussions, visual show, and a lecture. A score was created from the correct answers to 58 questions.

Results: A total of 400 male soldiers with mean age $30.7 \pm 6.1$ years completed both questionnaires. The majority had school education (96.8\%) and in the lower military ranks (66.0\%). Only $19.5 \%$ of soldiers reported HBV vaccine intake. The low median and inter-quartile range of the pre-intervention score $(16,6-26)$ markedly increased after education (to 53, 50-55, p<0.001). The overall improvement of mean KAP score (204\%) was also observed in all its component scores; disease nature (272\%), methods of transmission (206\%), prevention and control (109\%), attitude (155\%), and practice (192\%). The improvement was evident irrespective of socio-demographic characteristics and history of HBV vaccine. KAP scores were significantly associated with higher educational levels, higher monthly income, administrative jobs, and higher job ranks.
\end{abstract}

Conclusion: We are reporting a low level of HBV awareness among Saudi military population. The study confirms the need and effectiveness of focused multifaceted educational campaigns among the military population.

Keywords: Hepatitis B virus, Knowledge, Attitude and Practice, Military, Saudi Arabia

\section{Background}

Viral hepatitis, especially those caused by HBV, represents a worldwide significant cause of morbidity and mortality [1,2]. In SA, viral hepatitis represents a major public health problem. SA used to be among the countries which had the highest endemicity of seropositive hepatitis B surface antigen (HBsAg) [3]. Despite implementation of a childhood $\mathrm{HBV}$ vaccination program in

\footnotetext{
* Correspondence: ThaqafiAO1@ngha.med.sa

${ }^{1}$ Infection Prevention and Control, King Abdulaziz Medical City, Jeddah, Saudi Arabia

Full list of author information is available at the end of the article
}

1990, HBV is currently reported more frequently among Saudi than the hepatitis C virus [4]. Moreover, according to the Saudi Ministry of Health $(\mathrm{MOH})$ data, viral hepatitis was ranked the second most common reportable viral disease after chickenpox, with more than 5000 new cases diagnosed in 2009 [4]. Jeddah, a multicultural coastal city, reported new HBV infections, the risk level being $50 \%$ higher than any other city in SA [4].

Lack of awareness of the risk of HBV and its consequences are recognized as a major deterrent to immunization among HBV high risk groups [5]. The incidence and prevalence HBV seropositivity ranked the

\section{Biomed Central}


second reportable communicable disease among SA National Guard (SANG) personnel in all regions and the first among SANG personnel in Jeddah [6]. Although the risk of HBV seropositivity was reported to be higher in the military population than the general population of SA $[7,8]$ and elsewhere $[9,10]$, and despite the fact that HBV seropositivity in SA was one of the highest in the world, [3] there was a definite lack of studies assessing KAP among military personnel of SA. However, there is a couple of studies examining awareness of HBV in SA among dental professionals [11] and patients [12]. Moreover, it appeared that the non-professional Saudi population had little or no knowledge of HBV [12]. The objective of this study was to evaluate the KAP of HBV infection before and after an educational intervention among SANG soldiers.

\section{Methods}

\section{Population}

The current study was conducted among SANG soldiers in Jeddah, SA. Jeddah governorate is located within the Western Region of SA and is considered the main Saudi seaport and, the main entrance for Makkah pilgrims. The population of Jeddah in 2009 was estimated at 3.3 million including 1.5 million non-Saudi [4]. Of the Saudi population, there was an estimated 10,000 male SANG soldiers serving in Jeddah. The population receives health services mainly by the Health Affairs of National Guard who provide one tertiary hospital and five primary healthcare centers.

\section{Study design}

An intervention design with pre- and post-education assessment of KAP of HBV infection was completed among the male SANG soldiers working in Jeddah during January 2009. Four hundred participants were randomly selected from the SANG soldiers roster and the consent form was signed after a verbal explanation of the study objectives. The participation rate was $96 \%$ and all participants completed both pre- and postintervention questionnaires. The KAP of HBV infection was assessed using a structured questionnaire completed immediately before and after the educational intervention. The study design obtained all required ethical approvals from the ethical committees of King Abdulaziz Medical Cities in Jeddah and Riyadh.

\section{Questionnaire}

The self-administered questionnaire was developed to assess the KAP of HBV infection among the study participants and the questions were based on previous surveys with similar objectives $[13,14]$. Additionally, the validity of the questionnaire was tested after Arabic translation. The lexical equivalence of questionnaire was examined after back translation. Content validity was established by a panel of experts from infectious disease medicine, public health, community medicine, epidemiology, biostatistics, and health education. The final version of the questionnaire had a good indicator for reliability (as indicated by Alpha Cronbach test value of 0.82). Sections of the administered questionnaire included identification data, personal and socio-demographic characteristics, general health status, and KAP of HBV infection which included 58 questions.

\section{Educational intervention}

It was established according to the standard principles of designing and implementing a health education program [15]. The content of the educational intervention included standard information pertaining to risk, transmission, and protection of $\mathrm{HBV}$ as described by the World Health Organization and the US Centers for Disease Control and Prevention $[2,5,16]$. The educational intervention was provided through (1) Distributing educational leaflets (including HBV facts, risk factors, hazard to population, misconceptions and misunderstanding of HBV, prevention tools and how to deal with an infected person), (2) Guiding group discussions followed by individual instructorparticipant discussions, (3) Attending mini-exhibition round and visual show, and (4) Presenting a PowerPoint lecture titled "Know and Participate to prevent HBV". The intervention was carried over 20 days with one session per day. Each session lasted 3 hours and included only 20 new participants to allow for personal communication and open discussion.

\section{Statistical analysis}

Data were presented using descriptive statistics in the form of frequencies and percentages for categorical data, and median and inter-quartile range (IQR) for continuous data. Overall KAP score was the sum of correct responses to the 58 questions. One point was given for the correct answer and zero for the wrong answer. Components' scores included knowledge of HBV disease nature (19 questions), transmission (25 questions), prevention and control (6 questions), attitude (3 questions), and practice (5 questions). KAP score and its components' scores were treated as non-parametric data and compared between pre- and post-intervention using Wilcoxon signed rank test. Both pre- and post-intervention KAP scores and their components' scores were compared across sociodemographic characteristics using Mann-Whitney test or Kruskal Wallis test, as appropriate. Qualitative variables were compared using chi-square test or Fisher exact test as appropriate. All P-values were two-tailed. P-value $<0.05$ was considered as significant. SPSS software (release 16.0, SPSS Inc., Chicago, U.S.) was used for all statistical analyses. 


\section{Results}

A total of 400 male soldiers were examined in the current study as shown in Table 1 . The mean age was $30.7 \pm 6.1$ years (median 29 and IQR, 26-34; range 21-48 years). Few soldiers could not read and write $(1.0 \%)$ or had university degrees (2.2\%) while the majority of the soldiers $(96.8 \%)$ had school education typically secondary education (43.5\%). The majority of the soldiers (78.5\%) were married. In addition, the majority of soldiers $(81.0 \%)$ reported monthly income between 3000 and 8000 Saudi Riyals with $61.5 \%$ describing their income as sufficient. Almost two-thirds $(63.8 \%)$ of the soldiers were engaged in technical jobs while around one-third (36.2\%) were engaged in administrative jobs. The majority (66\%) of

Table 1 Overall knowledge, attitude and practice (KAP) scores before and after educational intervention by sociodemographic characteristics among SANG soldiers (Jeddah, 2009)

\begin{tabular}{|c|c|c|c|c|}
\hline \multirow[t]{2}{*}{ Characteristics } & \multirow{2}{*}{$\begin{array}{c}N(\%) \\
\text { mean } \pm S D\end{array}$} & Overall KAP score & \multirow{2}{*}{$\begin{array}{l}\text { Post-intervention } \\
\text { Median (IQR) }\end{array}$} & \multirow{2}{*}{$\begin{array}{c}\mathrm{p}- \\
\text { value }\end{array}$} \\
\hline & & Pre-intervention Median (IQR) & & \\
\hline Overall & $400(100.0 \%)$ & $16(6-26)$ & $53(50-55)$ & $<0.001$ \\
\hline Age (mean $\pm S D$, years) & $30.7 \pm 6.1$ & & & \\
\hline Age groups & & $P^{* *}=0.086$ & $P^{* *}=0.107$ & \\
\hline$<25$ years & $57(14.3 \%)$ & $15(4.5-25.5)$ & $54(50.5-55)$ & $<0.001$ \\
\hline 25-34 years & $256(64.0 \%)$ & $15(6-24)$ & $53(51-54)$ & $<0.001$ \\
\hline $35+$ years & $87(21.8 \%)$ & $19(8-30)$ & $52(49-54)$ & $<0.001$ \\
\hline Educational level & & $P^{* *}=0.007$ & $P<0.001$ & \\
\hline Elementary or lower & $83(20.8 \%)$ & $14(5-21)$ & $50(45-53)$ & $<0.001$ \\
\hline Intermediate & $134(33.5 \%)$ & $14.5(6-22.3)$ & $53(50-55)$ & $<0.001$ \\
\hline Secondary or higher & $183(45.8 \%)$ & $19(6-30)$ & $54(52-55)$ & $<0.001$ \\
\hline Marital status & & $P^{* *}=0.358$ & $P^{* *}=0.284$ & \\
\hline Single or divorced & $86(21.5 \%)$ & $14.5(5-25.3)$ & $52.5(50-54)$ & $<0.001$ \\
\hline Married & $314(78.5 \%)$ & $16.5(6-26)$ & $53(50-55)$ & $<0.001$ \\
\hline Monthly income, amount & & $P^{* *}=0.001$ & $P^{* *}=0.004$ & \\
\hline$\leq 8000 \mathrm{SR}$ & $324(81.0 \%)$ & $15(5-24)$ & $53(50-54)$ & $<0.001$ \\
\hline$>8000 \mathrm{SR}$ & $76(19.0 \%)$ & $20.5(10.5-31)$ & $54(52-55)$ & $<0.001$ \\
\hline Monthly income, sufficiency & & $P^{* *}=0.338$ & $P^{* *}=0.228$ & \\
\hline Sufficient & $246(61.5 \%)$ & $16(5-26)$ & $53(50-55)$ & $<0.001$ \\
\hline Insufficient & $154(38.5 \%)$ & $17(7-26.3)$ & $53(49-54)$ & $<0.001$ \\
\hline Type of the job & & $P^{* *}=0.005$ & $P^{* *}=0.026$ & \\
\hline Technical & $255(63.8 \%)$ & $14(5-24)$ & $53(49-54)$ & $<0.001$ \\
\hline Administrative & $145(36.2 \%)$ & $19(9-28)$ & $53(51-55)$ & $<0.001$ \\
\hline Rank & & $P^{* *}=0.026$ & $P^{* *}=0.007$ & \\
\hline Soldier & $138(34.5 \%)$ & $14(4.8-23.3)$ & $53(49-54)$ & $<0.001$ \\
\hline First soldier & $126(31.5 \%)$ & $15.5(6-24.3)$ & $52.5(50-54)$ & $<0.001$ \\
\hline Corporal or higher & $136(34.0 \%)$ & $19.5(7.3-29.8)$ & $54(51-55)$ & $<0.001$ \\
\hline Service years (mean $\pm S D$ ) & $10.0 \pm 6.8$ & & & \\
\hline Duration of service groups & & $P^{* *}=0.542$ & $P^{* *}=0.123$ & \\
\hline$<5$ years & $102(25.5 \%)$ & $15.5(5-26.3)$ & $53(51-55)$ & $<0.001$ \\
\hline $5-9$ years & $125(31.3 \%)$ & $15(6-24.5)$ & $53(51-55)$ & $<0.001$ \\
\hline$\geq 10$ years & $173(43.3 \%)$ & $18(6.5-27)$ & $53(49-54)$ & $<0.001$ \\
\hline History of HBV vaccine & & $P^{* *}=0.039$ & $P^{* *}=0.081$ & \\
\hline No or don't know & $322(80.5 \%)$ & $15(5-26)$ & $53(50-54)$ & $<0.001$ \\
\hline Yes & 78 (19.5\%) & 19 (9.8-27.8) & $53.5(51-55)$ & $<0.001$ \\
\hline
\end{tabular}

$\mathrm{N}(\%)$, frequency and percentage; Mean $\pm S D$, mean and standard deviation; IQR, inter-quartile range; SR, Saudi Riyals. *Wilcoxon signed rank test ** Mann-Whitney test or Kruskal Wallis test as appropriate. 
Table 2 Frequency of correct answers for individual knowledge, attitude, and practice (KAP) questions of the pre- and post-intervention questionnaires among SANG soldiers (Jeddah, 2009)

\begin{tabular}{|c|c|c|c|c|c|}
\hline \multirow[t]{2}{*}{ Questionnaire questions } & \multicolumn{2}{|c|}{ Intervention } & \multirow[t]{2}{*}{ Questionnaire questions } & \multicolumn{2}{|c|}{ Intervention } \\
\hline & Pre & Post & & Pre & Post \\
\hline Knowledge of HBV nature & & & Knowledge of HBV transmission & & \\
\hline $\mathrm{HBV}$ is an infectious disease & $133(33.3 \%)$ & $391(97.8 \%)$ & Using other person's toothbrush & $133(33.3 \%)$ & $394(98.5 \%)$ \\
\hline Organs affected by HBV & $213(53.3 \%)$ & 398 (99.5\%) & Dentist tools & $171(42.8 \%)$ & $398(99.5 \%)$ \\
\hline The type of causative microorganism & $142(35.5 \%)$ & $394(98.5 \%)$ & Razor & $165(41.3 \%)$ & $397(99.3 \%)$ \\
\hline Infected person will remain infected for life & $70(17.5 \%)$ & $252(63.0 \%)$ & Surgery tools & $190(47.5 \%)$ & $397(99.3 \%)$ \\
\hline Can transmit through the family members & $134(33.5 \%)$ & $351(87.8 \%)$ & Circumcision tools & $150(37.5 \%)$ & $396(99.0 \%)$ \\
\hline HBV is easily transmitted than AIDS & $53(13.3 \%)$ & $361(90.3 \%)$ & Cupping " Hijamah" tools & $171(42.8 \%)$ & $393(98.3 \%)$ \\
\hline Can be diagnosed from external appearance & $96(24.0 \%)$ & $302(75.5 \%)$ & Acupuncture needles & $161(40.3 \%)$ & $392(98.0 \%)$ \\
\hline When to call the disease as chronic & $55(13.8 \%)$ & $358(89.5 \%)$ & Nails clipper & $62(15.5 \%)$ & $395(98.8 \%)$ \\
\hline The percentage of chronic disease & $7(1.8 \%)$ & $244(61.0 \%)$ & Sewak (tooth cleaner) & $113(28.3 \%)$ & $397(99.3 \%)$ \\
\hline HBV has complications & $121(30.3 \%)$ & $378(94.5 \%)$ & Ear or nose piercing & $67(16.8 \%)$ & $387(96.8 \%)$ \\
\hline Most of the liver tumors are caused by HBV & $70(17.5 \%)$ & $333(83.3 \%)$ & Tattooing & $81(20.3 \%)$ & $391(97.8 \%)$ \\
\hline Infected person may develop liver cirrhosis & $128(32.0 \%)$ & $390(97.5 \%)$ & Knowledge of HBV preventive and control & & \\
\hline Infected person may develop cancer & $76(19.0 \%)$ & $376(94.0 \%)$ & Availability of any protection against HBV & $195(48.8 \%)$ & $390(97.5 \%)$ \\
\hline HBV could lead to death & $142(35.5 \%)$ & $378(94.5 \%)$ & Availability of vaccine against HBV & $202(50.5 \%)$ & $386(96.5 \%)$ \\
\hline Knowledge of HBV transmission & & & Pregnant women should do HBV screening & $162(40.5 \%)$ & $391(97.8 \%)$ \\
\hline Blood & $232(58.0 \%)$ & $399(99.8 \%)$ & $\begin{array}{l}\text { Family members of patients should do } \\
\text { investigations for HBV }\end{array}$ & $292(73.0 \%)$ & $394(98.5 \%)$ \\
\hline Sexual intercourse & $159(39.8 \%)$ & 398 (99.5\%) & Availability of medical treatment & $184(46.0 \%)$ & $364(91.0 \%)$ \\
\hline From infected mother to the fetus & $120(30.0 \%)$ & $392(98.0 \%)$ & Possibility of complete cure & $17(4.3 \%)$ & $272(68.0 \%)$ \\
\hline From asymptomatic infected person & $99(24.8 \%)$ & $336(84.0 \%)$ & Attitude towards HBV patients & & \\
\hline Breast feeding & $31(7.8 \%)$ & $358(89.5 \%)$ & Dealing with infected household person & $181(45.3 \%)$ & $279(69.8 \%)$ \\
\hline Shaking hands & $166(41.5 \%)$ & $376(94.0 \%)$ & $\begin{array}{l}\text { Isolating infected person from } \\
\text { work/daily activity }\end{array}$ & $135(33.8 \%)$ & $373(93.3 \%)$ \\
\hline Hugging & $124(31.0 \%)$ & $363(90.8 \%)$ & Using toilet after an infected person & $39(9.8 \%)$ & $253(63.3 \%)$ \\
\hline Contaminated clothes & $54(13.5 \%)$ & $369(92.3 \%)$ & Practices of $\mathrm{HBV}$ patients & & \\
\hline Sneezing & $52(13.0 \%)$ & $376(94.0 \%)$ & Eating food with his/her family & $112(28.0 \%)$ & $371(92.8 \%)$ \\
\hline Coughing & $51(12.8 \%)$ & $0(0.0 \%)$ & Sharing the eating tools with his/her family & $49(12.3 \%)$ & $306(76.5 \%)$ \\
\hline Eating food prepared by an infected person & $60(15.0 \%)$ & $346(86.5 \%)$ & Kissing his/her children & $114(28.5 \%)$ & $384(96.0 \%)$ \\
\hline Sharing food with an infected person & $95(23.8 \%)$ & $337(84.3 \%)$ & Shaking hand of his/her children & $186(46.5 \%)$ & $386(96.5 \%)$ \\
\hline Water drinking & $43(10.8 \%)$ & $267(66.8 \%)$ & Helping injured subject with open wound & $134(33.5 \%)$ & $293(73.3 \%)$ \\
\hline Using syringes or needles & $209(52.3 \%)$ & $396(99.0 \%)$ & & & \\
\hline
\end{tabular}

P-values of Chi Square tests comparing pre- and post-intervention questionnaires were $<0.001$ for all questions.

soldiers were in the lower military ranks (lower than Corporal). The average service duration at SANG was $10.0 \pm 6.8$ years (median 9 and IQR, 4-15). Only $19.5 \%$ of soldiers reported previous HBV vaccine intake. One-third (35.2\%) of the soldiers claimed they had some knowledge of HBV. The most common sources reported for such knowledge were TV/Radio (39.7\%), friends (36.9\%), and newspapers and magazines (26.9\%).

A significant $(\mathrm{p}<0.001)$ increase in the frequency of correct answers was shown in all general knowledge questions after educational intervention (Table 2). Those who correctly identified the infectious nature of HBV increased from $33.3 \%$ before intervention to $97.8 \%$ after intervention. Those who correctly recognized the possibility of developing complications in $\mathrm{HBV}$ patients increased from $30.3 \%$ before intervention to $94.5 \%$ after intervention. Those who correctly acknowledged major methods of HBV transmission as blood and sexual intercourse increased from $58.0 \%$ and $39.8 \%$, respectively before intervention to $99.8 \%$ and $99.5 \%$, respectively after intervention. Those who correctly recognized the possibility of infected dental and surgical tools to transmit $\mathrm{HBV}$ 
increased from $42.8 \%$ and $47.5 \%$, respectively before intervention to $99.5 \%$ and $99.3 \%$, respectively after intervention. Those who were aware of the availability of vaccine against HBV increased from $50.5 \%$ before intervention to $96.5 \%$ after intervention.

Similar to the general knowledge questions, attitude and practice questions also significantly improved after intervention $(\mathrm{p}<0.001$ for all). Those who expressed the correct attitude in cautiously dealing with an infected household person and not supporting isolation of that infected person from work or daily activity increased from $45.3 \%$ and $33.8 \%$, respectively before intervention to $69.8 \%$ and $93.3 \%$, respectively after intervention. Those who expressed their acknowledgement to some behaviors of HBV patients such as eating food with his/ her family and shaking hand of his/her children increased from $28.0 \%$ and $46.5 \%$, respectively before intervention to $92.8 \%$ and $96.5 \%$, respectively after intervention. Likewise those who denounced that $\mathrm{HBV}$ patients can help injured subject with an open wound increased from $33.5 \%$ before intervention to $73.3 \%$ after intervention.

The median (and IQR) of overall KAP score significantly increased from 16 (6-26) before intervention to 53 (50-55) after intervention ( $\mathrm{p}$-value of Wilcoxon signed rank test $<0.001$ ) (Table 1). This represented more than a $200 \%$ increase of post-intervention mean overall KAP score (Figure 1). The improvement of KAP components' scores were highest with HBV nature $(272 \%)$ and lowest with prevention and control (109\%) (Figure 1). The improvement of post-intervention overall KAP score was evident irrespective (after stratification) of age groups, education level, marital status, monthly income, job type or rank, duration of service, and history of HBV vaccine (Table 1). Using Mann-Whitney test or Kruskal Wallis test, both pre- and post-intervention, overall KAP scores were significantly associated (p-value <0.05) with higher educational levels, higher monthly income ( $>8000$ Saudi Riyals), administrative jobs, and higher job ranks but not marital status nor duration of service. Additionally, a pre-intervention overall KAP score was significantly associated with history of HBV vaccine $(\mathrm{p}=0.039)$ (Table 1$)$.

\section{Discussion}

The current study examined KAP of HBV infection among military personnel before and after educational intervention among SANG soldiers. We are reporting low pre-intervention knowledge levels. Common methods of HBV transmission such as blood transfusion, sexual intercourse, and childbirth acknowledged by our population before educational intervention were limited (58\%, 40\%, and $30 \%$, respectively) and were comparable to those reported by Saudi dental patients $(50-52 \%, 32-38 \%$, and $33-41 \%$, respectively). However, the level of knowledge in our SANG population was considerably lower than reported in the non-Saudi population with a relatively higher risk of HBV [17-19]. For example sexual intercourse and childbirth as a potential source of HBV were recognized by $69 \%$ and $83 \%$ (respectively) of Vietnamese American compared to $40 \%$ and 30\% (respectively) of SANG soldiers [18]. Similarly, blood transfusion and sexual intercourse were recognized by $93 \%$ and $68 \%$ (respectively) of Egyptian barbers and their clients compared to 58\% and

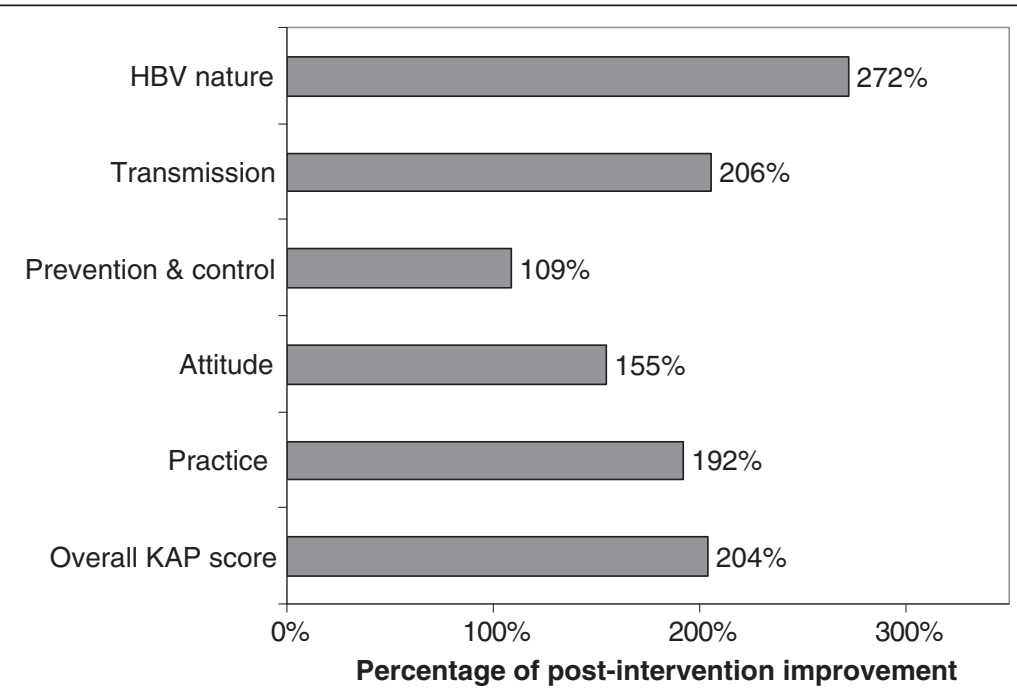

Figure 1 Percentage of post-intervention improvement of mean overall knowledge, attitude, and practice (KAP) score and its components' scores compared to pre-intervention scores among SANG soldiers (Jeddah, 2009). P-values using Wilcoxon signed rank tests for all scores' improvements were $<0.001$. 
$40 \%$ (respectively) of SANG soldiers [17]. Some of these differences may be understood given the highly conservative nature of the Saudi community who find it embarrassing to openly discuss issues such as sexually transmitted diseases or safe sex with partners. Moreover, the lack of health education campaigns targeting important health problems in military personnel may also have contributed to this serious absence of knowledge. The low level of HBV awareness observed among our SANG population before the intervention may reflect a similarly low level of HBV awareness in the general public in SA [12] which may be contributing to the endemicity of HBV.

The study results showed marked improvement of overall KAP scores and their components' scores after educational intervention. The observed post-intervention improvement among SANG soldiers was evident irrespective of socio-demographic characteristics and history of HBV vaccine intake. Similar results were reported using different educational methods in different populations $[20,21]$. A significant improvement in the knowledge of HBV prevention was observed in five Asian-American groups who completed self-administered tests before and after receiving lectures on hepatitis B prevention [20]. Additionally, in a randomized trial among Chinese Americans/ Canadians lay health worker, those who received standard HBV audiovisual and printed educational materials were able to recognize common methods of HBV transmission after 6-month from randomization significantly better than controls [21]. Similarly, a marked improvement (from $24 \%$ to $84 \%$ ) in knowledge of hepatitis C transmission was observed in secondary school students in France after an educational slide show. The improvement was independent of gender, age and geographical area [22]. Interestingly, the knowledge sub-score for HBV preventive and control in our SANG population had the poorest improvement score. This could simply be due to the higher level of preintervention knowledge of preventive and control compared to the disease nature, for example, which was the highest to improve.

The overall KAP score in our SANG population both before and after educational intervention was significantly associated with higher educational levels, higher monthly income, administrative jobs, and higher job ranks. These characteristics may be inter-correlated; for example those with higher education have higher-paid jobs and are more administratively inclined. HBV awareness in many populations was reported to correlate with the level of education $[12,13,23,24]$ and higher income $[12,24]$. Those with higher education or higher income probably have more and better access to educational resources such as internet as well as preventive care including physician advice.

The current study had many strengths including targeting a military population that has been ignored in previous KAP studies, large sample size $(\mathrm{N}=400)$, lower level of non-participation (4\%), and the absence of postintervention drop-outs that was shown in other studies [21]. Nevertheless, we acknowledge the limitations. Our findings cannot be projected to the general population as the military population is likely to have different exposures and is inherently more disciplined, as indicated by the high participation rate and completeness of postintervention survey. However, our military population had a level of pre-intervention knowledge similar to other members of the SA population [12]. Additionally, our design assessed the immediate post-intervention KAP level and, therefore, cannot be extended to long-term improvement of KAP level. Future studies within the military population may need to focus on long-term sustainability of such improvement.

\section{Conclusion}

In conclusion, we are reporting a low level of HBV awareness among the Saudi military population. The study confirms the need and the effectiveness of focused multifaceted educational campaigns in improving KAP among the military population. Targeting military recruits may ensure earlier education and, most likely, protection.

\section{Competing interests}

All authors have no competing interests.

\section{Authors' contributions}

MT, designed the study, overviewed implementation, and drafted the manuscript. $\mathrm{HB}$, helped in drafting and critical review of the manuscript. ZM, participated in the study design and helped critical review of the manuscript. YM, participated in the study design and helped critical review of the manuscript. Al, participated in the study design and supervised statistical analysis. AA, participated in the study design and helped critical review of the manuscript. AT, supervised the study design and implementation and helped to draft the manuscript. All authors read and approved the final manuscript.

\section{Author details}

${ }^{1}$ Infection Prevention and Control, King Abdulaziz Medical City, Jeddah, Saudi Arabia. ${ }^{2}$ Infection Prevention and Control, King Abdulaziz Medical City, Riyadh, Saudi Arabia. ${ }^{3}$ Deputy Minister of Health for Public Health, Ministry of Health, Riyadh, Saudi Arabia. ${ }^{4}$ Family and Community Medicine, Ministry of Health, Jeddah, Saudi Arabia. ${ }^{5}$ Statistical Department, Primary Healthcare, Ministry of Health, Jeddah, Saudi Arabia. ${ }^{6}$ Pathology \& Laboratory Medicine, King Abdulaziz Medical City, Jeddah, Saudi Arabia.

Received: 8 August 2012 Accepted: 10 October 2012

Published: 30 October 2012

\section{References}

1. Shepard CW, Simard EP, Finelli L, Fiore AE, Bell BP: Hepatitis B virus infection: epidemiology and vaccination. Epidemiol Rev 2006, 28:112-125.

2. World Health Organization: Hepatitis B. (Fact sheet no. 204). Geneva, Switzerland: World Health Organization; 2008. URL: http://www.who.int/ mediacentre/factsheets/fs204/en/index.html (Last accessed May 15, 2012). 3. World Health Organization: Hepatitis B. Geneva: WHO; 2002.

4. Saudi Ministry of Health: A review of health situation, the annual health statistics book:; 2009. URL: http://www.moh.gov.sa/en/Ministry/Statistics/ book/Pages/default.aspx (Last accessed May 15, 2012). 
5. Centers for Disease Control and Prevention: In Epidemiology and prevention of vaccine-preventable diseases. 11th edition. Edited by Atkinson W, Wolfe S, Hamborsky J, Mclntyre L. Washington DC: Public Health Foundation; 2009.

6. Annual Report 2009: Surveillance of Infectious Diseases. Infection Prevention and Control Department, Infection Prevention and Control Department. Riyadh: National Guard Health Affairs; 2009.

7. Memish ZA, Knawy BA, El-Saed A: Incidence trends of viral hepatitis A, B, and $C$ seropositivity over eight years of surveillance in Saudi Arabia. Int J Infect Dis 2009, 14(2):e115-120.

8. El Beltagy KE, Al Balawi IA, Almuneef M, Memish ZA: Prevalence of hepatitis $B$ virus markers among blood donors in a tertiary hospital in Tabuk, northwestern Saudi Arabia. Int J Infect Dis 2008, 12(5):495-499.

9. Bauduceau O, Berlioz A, Buisson Y: Hepatitis B, C, and E in New Caledonia. Seroepidemiologic study in military recruits. Med Trop (Mars) 2000, 60(2):167-170.

10. Gelberg L, Robertson MJ, Leake B, Wenzel SL, Bakhtiar L, Hardie EA, Sadler N, Getzug T: Hepatitis B among homeless and other impoverished US military veterans in residential care in Los Angeles. Public Health 2001, 115(4):286-291.

11. Paul T, Maktabi A, Almas K, Saeed S: Hepatitis B awareness and attitudes amongst dental health care workers in Riyadh, Saudi Arabia. Odontostomatol Trop 1999, 22(86):9-12.

12. Ashri NY: Hepatitis $B$ and $C$ knowledge among Saudi dental patients. Saudi Med J 2008, 29(12):1785-1790.

13. Thompson MJ, Taylor VM, Yasui Y, Hislop TG, Jackson JC, Kuniyuki A, Teh C: Hepatitis B knowledge and practices among Chinese Canadian women in Vancouver, British Columbia. Can J Public Health 2003, 94(4):281-286.

14. Hislop TG, Teh C, Low A, Li L, Tu SP, Yasui Y, Taylor VM: Hepatitis B knowledge, testing and vaccination levels in Chinese immigrants to British Columbia, Canada. Can J Public Health 2007, 98(2):125-129.

15. Greenberg JS: Health education and health promotion. 5th edition. New York: McGraw-Hill; 2004

16. CDC: Hepatitis B; patient education resources. URL: http://www.cdc.gov/ hepatitis/B/PatientEduB.htm\#cdc (Last accessed May 15, 2012).

17. Shalaby S, Kabbash IA, El Saleet G, Mansour N, Omar A, El Nawawy A: Hepatitis B and C viral infection: prevalence, knowledge, attitude and practice among barbers and clients in Gharbia governorate, Egypt. East Mediterr Health J 2010, 16(1):10-17.

18. Taylor VM, Choe JH, Yasui Y, Li L, Burke N, Jackson JC: Hepatitis B awareness, testing, and knowledge among Vietnamese American men and women. J Community Health 2005, 30(6):477-490.

19. Taylor VM, Tu SP, Woodall E, Acorda E, Chen H, Choe J, Li L, Yasui Y, Hislop TG: Hepatitis B knowledge and practices among Chinese immigrants to the United States. Asian Pac J Cancer Prev 2006, 7(2):313-317.

20. Hsu CE, Zhang G, Yan FA, Shang N, Le T: What made a successful hepatitis B program for reducing liver cancer disparities: an examination of baseline characteristics and educational intervention, infection status, and missing responses of at-risk Asian Americans. J Community Health 2010, 35(3):325-335.

21. Taylor VM, Hislop TG, Tu SP, Teh C, Acorda E, Yip MP, Woodall E, Yasui Y: Evaluation of a hepatitis B lay health worker intervention for Chinese Americans and Canadians. J Community Health 2009, 34(3):165-172.

22. Gardella F, Marine-Barjoan E, Truchi R, Fodella L, Delasalle P, Sattonnet C, Gelsi EV, Saint-Paul MC, Ouzan D, Tran A: Hepatitis C awareness among adolescents in the Alpes-Maritimes area of France. Gastroenterol Clin Biol 2007, 31(5):485-492

23. Cheung J, Lee TK, Teh CZ, Wang CY, Kwan WC, Yoshida EM: Cross-sectional study of hepatitis B awareness among Chinese and Southeast Asian Canadians in the Vancouver-Richmond community. Can J Gastroenterol 2005, 19(4):245-249

24. Taylor VM, Jackson JC, Pineda M, Pham P, Fischer M, Yasui Y: Hepatitis B knowledge among Vietnamese immigrants: implications for prevention of hepatocellular carcinoma. J Cancer Educ 2000, 15(1):51-55.

\section{doi:10.1186/1756-0500-5-597}

Cite this article as: Al-Thaqafy et al:: Improvement of the low knowledge, attitude and practice of hepatitis B virus infection among Saudi national guard personnel after educational intervention. BMC Research Notes 2012 5:597.

\section{Submit your next manuscript to BioMed Central and take full advantage of:}

- Convenient online submission

- Thorough peer review

- No space constraints or color figure charges

- Immediate publication on acceptance

- Inclusion in PubMed, CAS, Scopus and Google Scholar

- Research which is freely available for redistribution 